\title{
Review
}

Acta Haematol 2019;142:21-29

DOI: $10.1159 / 000496965$
Received: November 22, 2018

Accepted after revision: January 11, 2019

Published online: April 10, 2019

\section{Management of Perioperative Iron Deficiency Anemia}

\author{
Susana Gómez-Ramírez ${ }^{\mathrm{a}} \quad$ Elvira Bisbe ${ }^{\mathrm{b}}$ Aryeh Shander ${ }^{\text {c, d }}$ Donat R. Spahn ${ }^{\mathrm{e}}$ \\ Manuel Muñoz ${ }^{\dagger}$ \\ ${ }^{a}$ Department of Internal Medicine, University Hospital Virgen de la Victoria, Málaga, Spain; ${ }^{b}$ Department of \\ Anesthesiology, University Hospital Mar-Esperanza, Barcelona, Spain; ' Departments of Anesthesiology, Critical Care, \\ and Hyperbaric Medicine, Englewood Hospital and Medical Center, Englewood, NJ, USA; dTeamHealth Research

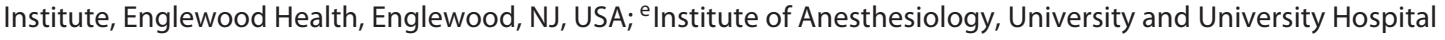 \\ of Zurich, Zurich, Switzerland; ${ }^{f}$ Department of Surgical Specialties, Biochemistry, and Immunology, School of \\ Medicine, University of Málaga, Málaga, Spain
}

\section{Keywords}

Anemia $\cdot$ Iron deficiency $\cdot$ Iron supplementation .

Recombinant erythropoietin · Surgery · Transfusion

\begin{abstract}
Preoperative anemia affects $30-40 \%$ of patients undergoing major surgery and is an independent risk factor for perioperative blood transfusion, morbidity, and mortality. Absolute or functional iron deficiency is its leading cause. Nonanemic hematinic deficiencies are also prevalent and may hamper preoperative hemoglobin optimization and/or recovery from postoperative anemia. As modifiable risk factors, anemia and hematinic deficiencies should be detected and corrected prior to major surgical procedures. Postoperative anemia is even more common (up to $80-90 \%$ ) due to surgery-associated blood loss, inflammation-induced blunted erythropoiesis, and/or preexisting anemia. Preoperative oral iron may have a role in mild-to-moderate anemia, provided there is sufficient time (6-8 weeks) and adequate tolerance of oral preparations. Postoperative oral iron is of little value and rife with gastrointestinal adverse events. Intravenous iron should preferentially be used in cases of moderate-tosevere iron deficiency anemia, concomitant use of erythropoiesis-stimulating agents, short time to surgery or nonelec-
\end{abstract}

tive procedures, and for postoperative anemia management. Minor infusion reactions to intravenous iron are rare, the incidence of severe anaphylactic reactions is extremely low, and there is no increase in infections with intravenous iron. Currently available intravenous iron formulations allowing administration of large single doses are preferred.

(c) 2019 S. Karger AG, Basel

\section{Introduction}

In daily clinical practice, the presence of anemia and its severity are defined according to the hemoglobin $(\mathrm{Hb})$ thresholds established by the World Health Organization (WHO) [1]. In the case of iron deficiency (ID) anemia (IDA), the WHO noted that "mild" is a misnomer, as ID is already advanced by the time anemia is detected and induces health consequences even when anemia is not clinically apparent [1].

Using WHO criteria, in 2010, one-third of the global population was anemic (over 2 billion people), and IDA remains the most common type of anemia worldwide ac-

Susana Gómez-Ramirez, Elvira Bisbe, and Manuel Muñoz are members of the Anemia Working Group España (AWGE).
Prof. Manuel Muñoz

Department of Surgical Specialties, Biochemistry, and Immunology School of Medicine, University of Málaga ES-29071-Málaga (Spain)

E-Mailmmunoz@uma.es 
counting for about one-half of the total anemia burden [2]. Increased iron demands, reduced absorption, and/or increased losses are the main causes of IDA. In a systematic analysis for the Global Burden of Disease Study 2016, IDA was the fourth leading cause of years lived with disability, especially in women, thus highlighting prevention and treatment of ID and IDA as a major public health goal [3].

\section{Prevalence and Consequences of Perioperative Anemia}

The WHO criteria for the definition of anemia may not be reliable for the classification of nonpregnant women undergoing surgical procedures with expected moderate-to-high blood loss $[4,5]$. Recently, a study of 1,388 women who underwent cardiac surgery revealed that "borderline" $\mathrm{Hb}$ concentrations (12.0-12.9 g/dL) were associated with increased red blood cell transfusion (RBCT) requirements and prolonged hospital stay compared to no anemia $(\mathrm{Hb} \geq 13 \mathrm{~g} / \mathrm{dL})$ [6]. Irrespective of gender, in patients scheduled for a major surgical procedure, a preoperative $\mathrm{Hb}<13 \mathrm{~g} / \mathrm{dL}$ should be considered as suboptimal $[4,5]$.

In a large cohort of major elective procedures $(n=$ $3,342)$, overall prevalence of anemia $(\mathrm{Hb}<13 \mathrm{~g} / \mathrm{dL})$ was $36 \%$, with differences between genders (53\% in women, $23 \%$ in men; $p<0.001$ ) and procedures (gynecologic surgery, $64 \%$; colorectal cancer, $58 \%$; cardiac surgery, $40 \%$; liver metastasis resection, $37 \%$; elective orthopedic surgery, 26\%; and radical prostatectomy, 8\%) [7]. Over 70\% of anemic patients presented with ID or functional ID (FID), resulting in iron-restricted erythropoiesis (IRE) [7]. As for nonelective procedures, up to $75 \%$ of patients undergoing hip fracture repair surgery $(n=1,004)$ presented with $\mathrm{Hb}<13 \mathrm{~g} / \mathrm{dL}$ on admission [8].

A meta-analysis including almost 950,000 noncardiac surgical procedures reported that preoperative anemia was linked to an increased risk of perioperative transfusion, morbidity (acute myocardial infarction, ischemic stroke, or kidney injury), and hospital and 30-day mortality [9]. In cardiac surgical procedures, preoperative anemia has also been shown to synergize with the negative effects of major blood loss and RBCT on mortality risk [10].

Preoperative hematinic deficiencies without anemia should also be considered. The emerging evidence that nonanemic ID is a disease in its own right that deserves attention because of the risk it poses for patients including the surgical population. In the above-mentioned study [7], 42\% of nonanemic patients presented with ID or FID and $27 \%$ with low iron stores (as defined by preoperative ferritin $<100 \mathrm{ng} / \mathrm{mL}$ ) [7]. Vitamin $B_{12}$ deficiency (defined as serum concentration $<270 \mathrm{pg} / \mathrm{mL}$ ) or folate deficiency (defined as serum concentration $<3 \mathrm{ng} / \mathrm{mL}$ ) are less frequent $(\approx 10 \%)$, but they should also be repleted in cases of deficiency [7]. These deficiencies may hamper preoperative $\mathrm{Hb}$ optimization and/or the recovery from postoperative anemia as well as increase postoperative morbidity. In 100 consecutive cardiac procedures, preoperative ID was frequent (37\%), and it was associated with preoperative anemia, higher RBCT requirements, and postoperative fatigue [11]. In a retrospective cohort of 277 cardiac surgeries, prevalence of ID was $39 \%$, and univariate analysis suggested that ID was associated with a longer hospital stay and fewer days alive out of hospital on postoperative day 90 [12]. In a retrospective cohort of 115 total hip arthroplasties at the first author's center, patients with ID ( $n=54: 45$ ID, 9 FID) have lower perioperative $\mathrm{Hb}$, higher prevalence of preoperative anemia, higher RBCT rate, without differences in pretransfusion $\mathrm{Hb}$, and a trend to longer hospital stays than those without ID [unpubl. data].

The prevalence of postoperative anemia after major surgery is even higher (up to $80-90 \%$ ), although it varies widely according to different definitions underlying medical conditions and the type of surgery performed [13]. Preoperative anemia, female gender, smaller body surface area, perioperative blood loss, and postoperative blunted erythropoiesis are the main factors contributing to postoperative anemia [14]. There are limited published data extant on the consequences of postoperative anemia in the recovery phase from surgery, but an association with poorer outcomes (prolonged recovery, early postoperative myocardial infarction, increased mortality, and likelihood of readmission) has been suggested [14].

Therefore, as modifiable risk factors, the presence of preoperative anemia $(\mathrm{Hb}<13 \mathrm{~g} / \mathrm{dL}$ for both genders) and hematinic deficiencies should be investigated prior to surgery, with expected moderate-to-high blood loss $(>500 \mathrm{~mL})$, as early as possible and ideally as soon as the decision to undergo surgery is made, but at least 4 weeks prior the scheduled procedure ("orthodox approach") [5]. For elective procedures, this may lead to the postponement of surgery with the intent of anemia treatment with the goal of resolution [5]. For nonelective procedures, any available time should be used to initiate treatment, which ultimately can be started or continued in the postoperative period $[5,14]$. It is recommended establishing a patient blood management expert group in 
Fig. 1. A pathway for preoperative anemia management [adapted from reference 5].

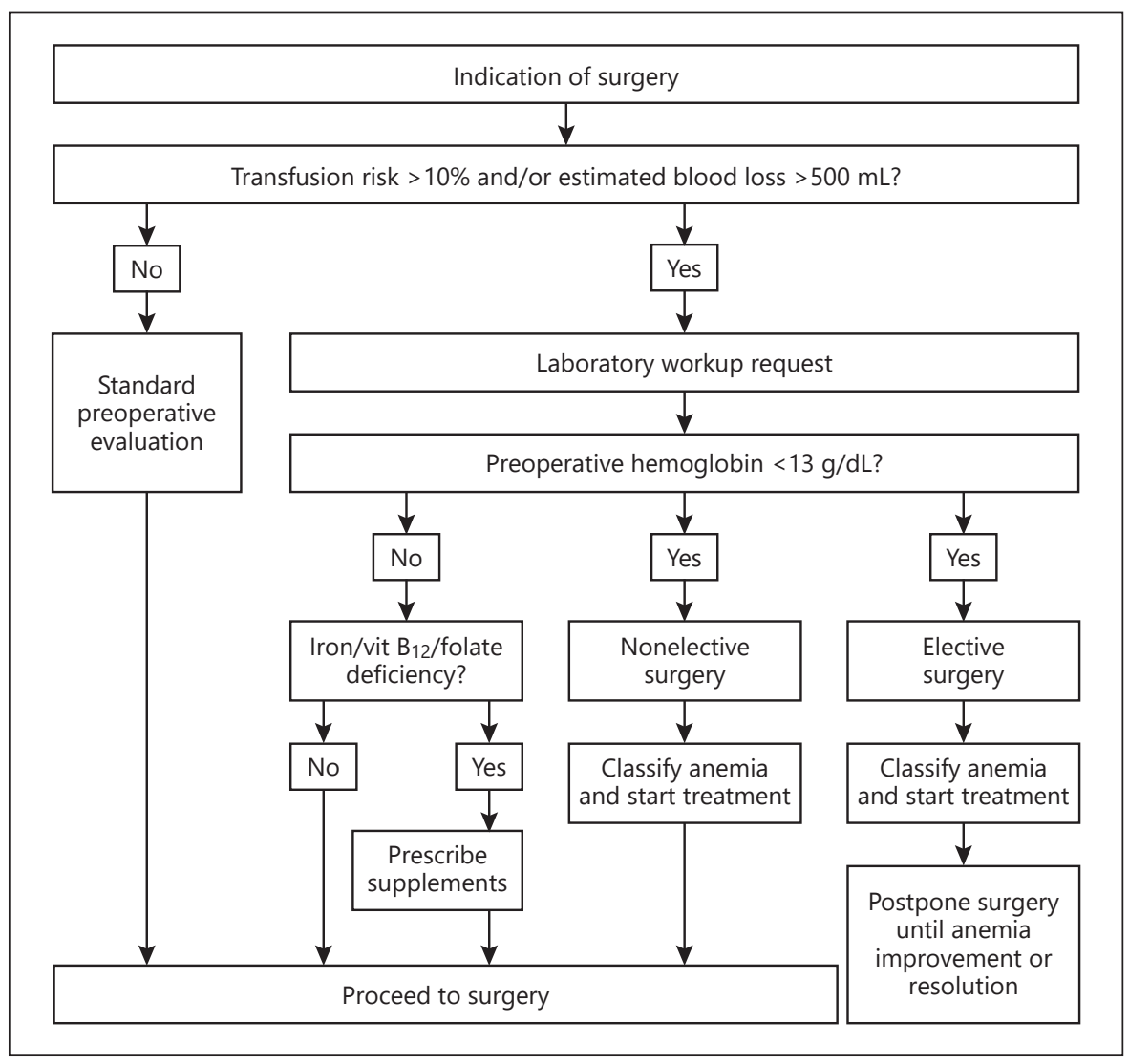

every hospital performing major surgical procedures, where a clear perioperative anemia management pathway should be in place (Fig. 1, 2) $[5,14]$.

Although level-one evidence for ID treatment in other conditions is established, the lack of such evidence for improved outcomes in the surgical population should not deter one from following good clinical practice, with the recommendation to diagnose and treat ID with or without anemia especially in those undergoing major surgery. Optimization of erythropoiesis is a fundamental pillar of patient blood management that improves patient outcomes $[8,15]$.

\section{Treatment Options for Iron Deficiency}

Until newer tests to determine iron need are validated (e.g., reticulocyte $\mathrm{Hb}$ content, hypochromic red blood cells, or soluble transferrin receptors), the transferrin saturation remains the most reliable tool to determine the need for iron $[5,16,17]$ (Fig. 3). The appropriate combination of different laboratory tests within an integrated algorithm will help to establish a correct diagnosis, avoid- ing the need for patients to return for another blood test and eliminating unnecessary laboratory studies $[16,17]$.

Following the diagnosis of ID, it is especially relevant to find and address the underlying cause, especially in unexplained and/or recurrent anemia, as well as to choose the appropriate therapeutic option that safely meets the patient's needs. ID should be treated with oral iron or intravenous iron, with or without recombinant human erythropoietin (rHuEPO), depending on the patient's $\mathrm{Hb}$ levels, anemia tolerance, and comorbidities, and not by resorting to RBCT. When pharmacologically treating preoperative anemia, the target $\mathrm{Hb}$ concentration should be $\geq 13 \mathrm{~g} / \mathrm{dL}$ (in both genders) to minimize the risk of RBCT-associated unfavorable outcomes [5].

\section{Oral Iron Supplementation}

The National Institute for Health and Care Excellence in the UK (NICE) recommends offering oral iron before or after surgery to patients with IDA [18]. Bioavailability of oral iron supplements given as ferrous or ferric salts is low and may be further decreased by proton pump inhibitors, antacids, meals, and inflammation [19,20]. Gastrointestinal side effects may reduce tolerance and adherence to iron 
Fig. 2. A pathway for postoperative anemia management [adapted from reference 14]. $\mathrm{Hb}$, hemoglobin; ID, iron deficiency; Post$\mathrm{OP}$, postoperative; RBCT, red blood cell transfusion.

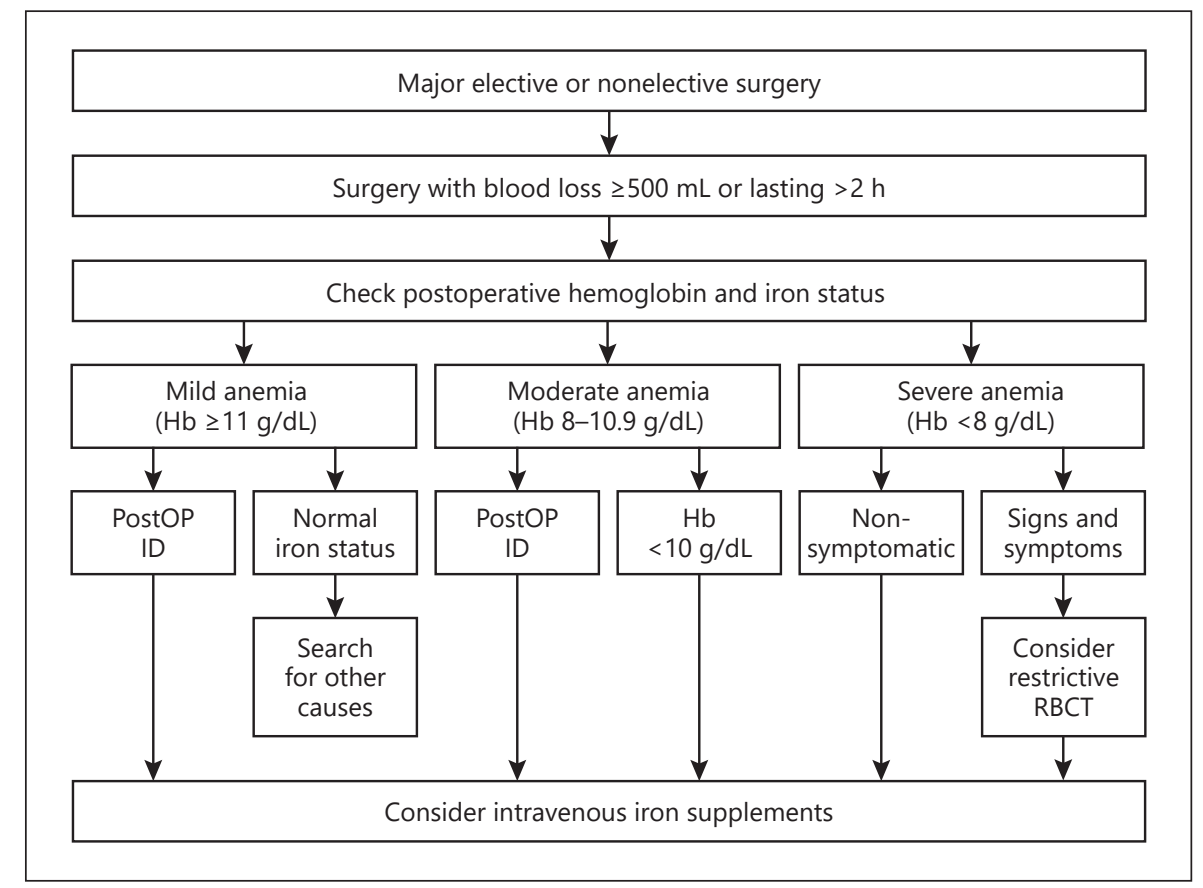

$\checkmark$ Iron repletion

- Ferritin $>100 \mathrm{ng} / \mathrm{mL}$ plus transferrin saturation $>20 \%$

$\checkmark$ Absolute iron deficiency

- Ferritin $<30 \mathrm{ng} / \mathrm{mL}$

Ferritin $30-100 \mathrm{ng} / \mathrm{mL}$ plus transferrin

saturation $<20 \%$ and/or C-reactive protein $>5 \mathrm{mg} / \mathrm{L}$

$\checkmark$ Iron sequestration

- Ferritin $>100 \mathrm{ng} / \mathrm{mL}$ plus transferrin saturation $<20 \%$

and/or C-reactive protein $>5 \mathrm{mg} / \mathrm{L}^{*}$

$\checkmark$ Low iron stores

- Ferritin $30-100 \mathrm{ng} / \mathrm{mL}^{* *}$ plus transferrin saturation $>20 \%$

Fig. 3. Iron status definitions. * More specific tests may be needed (e.g., reticulocyte hemoglobin content, hypochromic red blood cells, serum transferrin receptors) to confirm iron deficiency. ** For surgeries with expected hemoglobin drop $>3-4 \mathrm{~g} / \mathrm{dL}$ due to bleeding; $1 \mathrm{ng} / \mathrm{mL}$ ferritin $\approx 8 \mathrm{mg}$ stored iron [adapted from references $5,16,19]$.

supplementation $[19,20]$. Low single daily (<60 mg) [21] and/or alternate-day doses $(<100 \mathrm{mg})$ may reduce side effects and maximize fractional absorption [22]. In elderly IDA patients, a 2-month course of $50 \mathrm{mg}$ of elemental iron daily was as effective as $150 \mathrm{mg}$ daily at improving $\mathrm{Hb}$ and ferritin but with fewer gastrointestinal side effects [23]. In primary hip replacement, a retrospective study showed that, compared to no iron supplementation, liposome-encapsulated ferric pyrophosphate iron $(30 \mathrm{mg} /$ day for 3-4 weeks preoperatively) was well tolerated, reduced transfusion requirements and length of hospital stay, and resulted in higher Hb levels 30 days after discharge [24].

As oral iron supplementation requires a significant amount of time, when the interval before surgery is sufficient (at least 6-8 weeks) and no contraindications are present, supplementation with oral iron and nutritional advice may be appropriate for mild-to-moderate IDA and/ or nonanemic ID or insufficient iron stores [5]. This could be attempted while the patient is on the surgical waiting list, but it is rarely practiced, and $\mathrm{Hb}$ incremental rises are slow and poor $(<1 \mathrm{~g} / \mathrm{dL}$ ) [25-27] (Fig. 4) (see online suppl. Tables 1 and 2; for all online suppl. material, see www. karger.com/doi/10.1159/000496965). Confirmatory randomized controlled trials (RCTs) on the beneficial effects of preoperative oral iron supplementation are warranted.

As for postoperative oral iron, a review of 7 RCTs, including 804 orthopedic and cardiac surgery patients, showed that high-dose oral iron therapy (100-300 mg elemental iron/day) was not better than placebo in correcting postoperative anemia and/or reducing transfusion requirements, and was associated with significant gastrointestinal side effects [14] (see online suppl. Table 3). The vast majority of these studies did not include patients with preoperative anemia and/or iron deficiency, or confirmed 


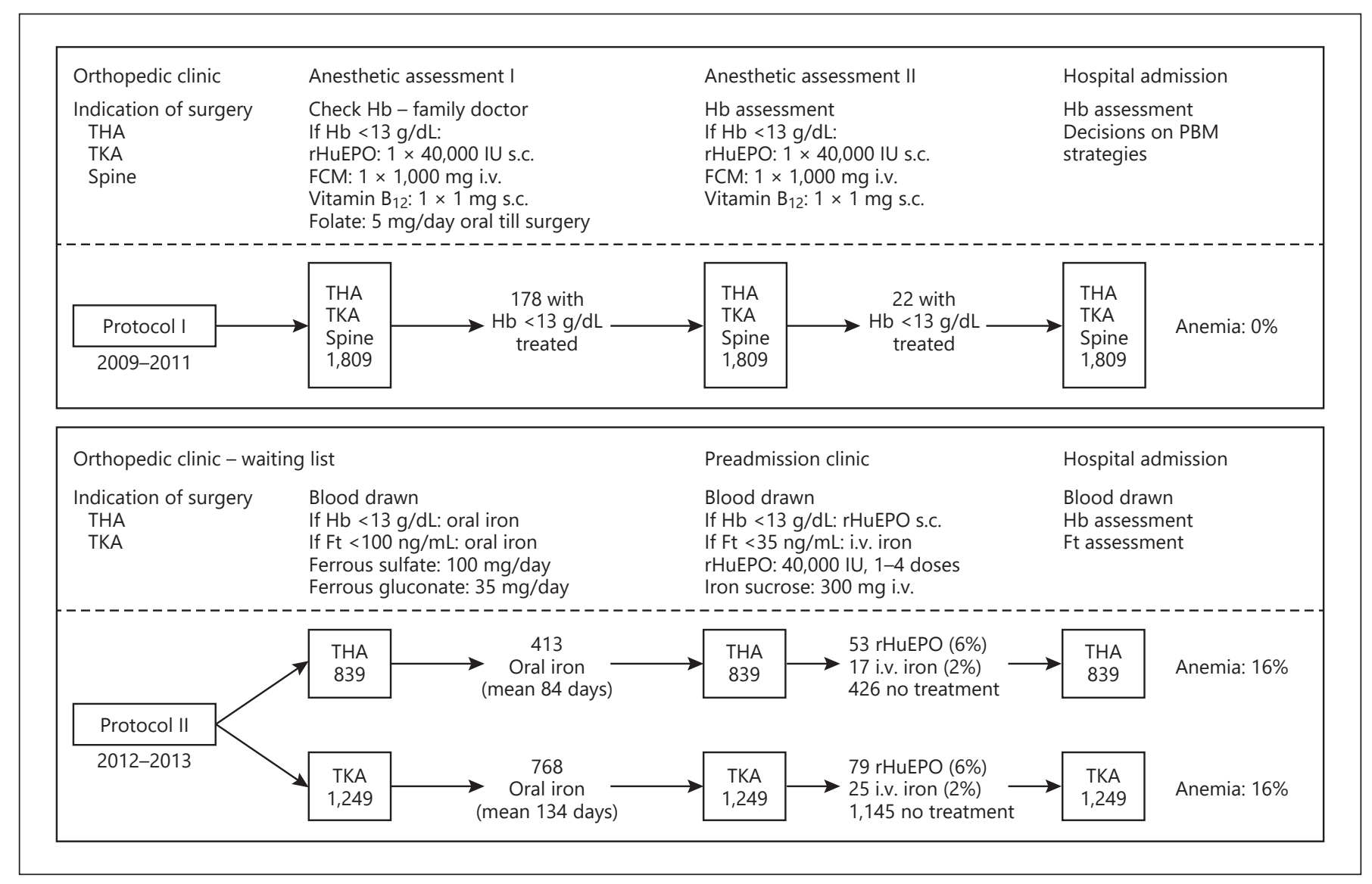

Fig. 4. Two clinical protocols for preoperative anemia management [data taken from 45 (protocol I) and 27 (protocol II)]. FCM, ferric carboxymatose; Ft, ferritin; Hb, hemoglobin; ID, iron deficiency; PBM, patient blood management; rHuEPO, recombinant human erythropoietin; THA, total hip arthroplasty; TKA, total knee arthroplasty.

postoperative iron deficiency; i.e., those who potentially could benefit the most from iron supplementation.

Even in the presence of ID, it is unlikely that postoperative administration of oral iron salts is effective in correcting anemia since the high levels of hepcidin, induced by surgical stress-associated inflammation, would inhibit intestinal absorption of oral iron [14, 28]. The results of the IRONOUT study in patients with chronic heart failure and ID seem to support the ineffectiveness of oral iron salts in the setting of inflammation [29].

\section{Intravenous Iron Supplementation}

In cases of intolerance to or ineffectiveness of iron salt, switching to intravenous iron may be appropriate [19]. In surgical patients, the intravenous route is preferred in cases of moderate-to-severe anemia, ongoing blood loss, inflammatory status, use of erythropoiesis-stimulating agents, short time to surgery, or nonelective procedures
[5]. Intravenous iron should also be preferred for management of moderate-to-severe postoperative anemia $(\mathrm{Hb}<10 \mathrm{~g} / \mathrm{dL})$, especially in patients with low preoperative iron stores [14]. As the response to intravenous iron is not immediate, not all postoperative RBCT could be avoided, but correction of ID and amelioration of anemia could improve patient performance [30].

The vast majority of published studies, especially in orthopedic and colorectal cancer surgery, support the preferential used of intravenous over oral iron for treating perioperative anemia (see online suppl. Tables 1, 2, and 4). In cardiac surgery, conflicting results have been found depending on whether intravenous iron was given with or without concomitant rHuEPO [31, 32]. Most guidelines from professional associations and international consensus documents recommend the administration of intravenous iron for the management of perioperative anemia $[5,14,33-35]$. 
Different intravenous iron formulations are commercially available for clinical use. These include ferric gluconate, iron sucrose, low-molecular-weight iron dextran, ferric carboxymaltose (FCM), ferumoxytol, or iron isomaltoside 1000. All of these formulations have been shown to have a dose-dependent efficacy for correcting ID $[19,36]$. Intravenous iron formulations are increasingly safer, though they are more expensive than oral iron, and there is a need for venous access and monitoring. While uncommon, minor infusion reactions, consisting of pressure in the chest or back, or flushing, resolve without intervention and should not be misconstrued or treated as anaphylaxis. Based on the preponderance of published evidence, it is inappropriate to intervene with vasopressors and/or antihistamines, which are responsible for virtually all serious adverse events ostensibly attributed to intravenous iron [37]. The incidence of severe anaphylactic reactions is extremely low $(\approx 1$ in 250,000 administrations), but it should not be overlooked [38]. As with the administration of any intravenous medication, practitioners should be prepared to manage serious acute hypersensitivity with standard measures, not specific to intravenous iron. The European Medicines Agency stated that "IV iron products should be administered only when staff trained to evaluate and manage anaphylactic reactions, as well as resuscitation facilities, are immediately available" [39]. An algorithm for scaling the intensity of treatment of hypersensitivity reactions during intravenous iron infusion to the clinical picture and/or response to therapy has been recently published [38]. Other nonevidence-based concerns regarding intravenous iron supplementation in surgical patients, such as increased risk of infection, iron overload, or oxidative stress, have also been refuted $[19,33,40]$. FCM is associated with a high incidence of moderate-to-severe hypophosphatemia, which may persist for weeks or months [41, 42] [for a complete discussion on the safety of iron supplementation, see the article by DeLoughery et al. in this issue].

Of note, intravenous iron formulations which allow short-time (15-60 min) infusion of high iron doses (1,000 mg or more), such as low-molecular-weight iron dextran, FCM, isomaltoside 1000, or ferumoxytol, are preferred by both physicians and patients compared to ferric gluconate or iron sucrose $[19,36]$.

\section{Recombinant Human Erythropoietin}

The administration of rHuEPO should be considered for patients with anemia of chronic inflammation and no contraindications to $\mathrm{rHuEPO}$ in addition to treating the underlying disease [43-47]. Elderly patients with anemia of unknown etiology, kidney diseases, or mild/moderate myelodysplastic syndrome often have good responses to rHuEPO administration, although adequate iron supplementation should always be ensured, preferably via the intravenous route [16].

In Europe, $\mathrm{rHuEPO}$ is licensed for improving preoperative $\mathrm{Hb}$ levels and reducing $\mathrm{RBCT}$ rates in patients undergoing elective orthopedic surgery with $\mathrm{Hb}$ between 10 and $13 \mathrm{~g} / \mathrm{dL}$ and expected to have moderate blood loss. In a recent meta-analysis (7 RCTs, 1,221 knee or hip arthroplasties), compared to a control group (placebo or no treatment), preoperative $\mathrm{rHuEPO}$ administration (generally, 3-4 × 40,000 IU) resulted in lower RBCT rates (odds ratio $[\mathrm{OR}]=0.41 ; 96 \%$ confidence interval $[\mathrm{CI}]=0.28-0.60 ; p=$ $0.0001)$ and less units transfused $(\mathrm{OR}=-0.45 ; 95 \% \mathrm{CI}=$ -0.68 to $-21 ; p=0.0002$ ), while $\mathrm{Hb}$ levels were higher at all perioperative time points (day of surgery and $24-48 \mathrm{~h}$ and 3-5 days postoperatively, or at discharge) [43].

Several observational studies and a recent RCT have also reported on the beneficial effects of fewer rHuEPO doses in orthopedic patients, especially when combined with intravenous iron within a patient blood management program $[25,27,44,45]$ (see online suppl. Table 2). Theusinger et al. [45] reported on the results of a "pragmatic approach" for patients presenting to the anesthesiologist at least 4 weeks prior to major orthopedic surgery $(n=1,985)$. Those with anemia $(\mathrm{Hb}<13 \mathrm{~g} / \mathrm{dL} ; n=178)$ received FCM (1,000 mg i.v.), rHuEPO (40,000 IU s.c.) and vitamin $B_{12}$ (1 mg s.c.), plus oral folic acid (5 mg/day for 4 weeks) and were reassessed 14 days later. If $\mathrm{Hb}$ remained $<13 \mathrm{~g} / \mathrm{dL}$, they received an additional dose of FCM $(1,000 \mathrm{mg}), \mathrm{rHu}$ EPO (40,000 IU), and vitamin $\mathrm{B}_{12}(1 \mathrm{mg})(n=27)$. All treated patients presented with normal $\mathrm{Hb}$ levels $(\geq 13 \mathrm{~g} /$ $\mathrm{dL}$ ) on the day of surgery. These results favorably compared with those reported by Petis et al. [27] on 2,088 patients scheduled for lower limb arthroplasties, of whom $57 \%$ received oral iron between surgery indication and preoperative assessment. Additionally, 132 received $\mathrm{rHu}-$ EPO (40,000 IU, 1-4 doses) and 42 intravenous iron sucrose (300 mg) between preoperative assessment and the day of surgery, when $16 \%$ were still anemic. The lower intravenous iron dose might have accounted for the difference in anemia prevalence on the day of surgery compared to the study by Theusinger et al. [45] (Fig. 3).

The possible role of off-label use of rHuEPO in cardiac and gastrointestinal cancer surgery has also been explored. In cardiac surgery, preoperative administration of $\mathrm{rHu}-$ EPO, with or without intravenous iron, significantly increased preoperative $\mathrm{Hb}$ levels, reduced $\mathrm{RBCT}$ requirements, and/or decreased postoperative major complica- 
tions and length of stay when compared to a control group $[31,46,47]$. In gastrointestinal cancer, a pooled-data analysis (6 RCTs, 621 patients) showed that perioperative treatment with $\mathrm{rHuEPO}$ did not reduce RBCT rate (33 vs. $37 \%$; OR: $0.89 ; p=0.206$ ) [48]. The increasing use of $r H u E P O$ in oncologic surgery (due to short-term use and positive $\mathrm{Hb}$ response) is also supported by the lack of convincing evidence on $\mathrm{rHuEPO}$ affecting cancer-related mortality or disease progression $[49,50]$. The administration of rHuEPO is still off label for patients undergoing potentially curative cancer surgery [51]. A benefit in RBCT rate reduction has been observed in most studies in which very short-term perioperative $\mathrm{rHuEPO}$, with or without intravenous iron, was administered to patients undergoing lower limb arthroplasty, hip fracture repair, or cardiac surgery ("opportunity approach") (see online suppl. Table 5). However, some guidelines do not support the off-label use of this agent [18]. A call for reevaluation of some of the persistent misconceptions of rHuEPO use based on current off-label use and improved $\mathrm{Hb}$ levels and $\mathrm{RBCT}$ reduction has yet to generate changes in labeling or restriction, although in the US, the Federal Drug Administration has relaxed some of the risk mitigation requirements of the use of rHuEPO.

\section{Red Blood Cell Transfusion}

RBCT should be restricted to those with severe IDA, poor physiological reserve, and/or acute symptoms requiring immediate correction, using the minimal amount necessary to achieve clinical stability. In surgical patients, $\mathrm{RBCT}$ is associated with increased risk of infection, circulatory overload, thromboembolic events, prolonged hospitalization, impaired quality of life, cancer recurrence, and mortality, and should be minimized or avoided [5257]. A restrictive RBCT policy and transfusing $1 \mathrm{RBC}$ unit at a time, with post-RBCT reassessment, are strongly recommended by most guidelines [5, 14, 18, 32-35, 58].

A critical literature review showed that patient-adapted, restrictive transfusion criteria are safe and effective in reducing both RBCT rates and RBCT volumes [59]. Most of these RCTs presented some serious drawbacks: (1) inclusion of a selected patient population, with strict inclusion and exclusion criteria, which may preclude a general applicability of results; (2) decisions on RBCT are made almost exclusively on the basis of a predefined transfusion threshold; and, most important, (3) no other anemia treatments are applied, and patients commonly maintained low $\mathrm{Hb}$ levels during hospitalization and at discharge.

In most but not all cases, RBCT produces a rapid, albeit transient, rise in $\mathrm{Hb}$ that increases oxygen-carrying capacity and alleviates anemia symptoms. Severe IDA will recur unless the underlying cause is identified and addressed when possible. After stability has been achieved with RBCT, additional pharmacological treatment should be considered (e.g., intravenous iron, rHuEPO) [14, 60, 61].

\section{Recommendations}

- In every hospital performing major surgical procedures, a clear perioperative anemia management pathway should be implemented.

- In major surgery, a preoperative $\mathrm{Hb}<13 \mathrm{~g} / \mathrm{dL}$ should be considered suboptimal in men and women, and requires to be improved prior to the procedure.

- Preoperative anemia should be detected, diagnosed, and properly treated prior to major surgery. For elective procedures, this may need the postponement of surgery with the intent of anemia treatment with the goal of resolution.

- Iron deficiency without anemia should be treated to optimize preoperative iron stores and hasten the recovery from postoperative anemia.

- When prescribing oral iron, consider low single doses $(<100 \mathrm{mg})$ on alternate days to improve absorption and tolerability.

- In case of immediate surgery or postoperative anemia, the vast majority of published studies support the preferential use of intravenous iron over oral iron, and intravenous iron formulations which allow short-time infusion (15-60 min) of high iron doses ( $\geq 1,000 \mathrm{mg})$ are generally preferred.

- Consider rHuEPO (1-2 × 40,000 IU) with intravenous iron for patients with $\mathrm{Hb}<13 \mathrm{~g} / \mathrm{dL}$ and inflammation or not adequately responding to intravenous iron if no contraindications are present, and provide adequate pharmacological thromboembolic prophylaxis.

- When pretreatment $\mathrm{Hb}$ is low, it would be advisable to check the response to anemia therapy after 2 weeks, and all treated patients should have an $\mathrm{Hb}$ assessment on the day of surgery.

- RBCT should be restricted to those with severe IDA, poor physiological reserve, and/or acute symptoms requiring immediate correction, using the minimal amount necessary to achieve clinical stability, and followed by pharmacological anemia treatment.

\section{Statement of Ethics}

The authors have no ethical conflicts to disclose. 


\section{Disclosure Statement}

In relation with the content of this review article: S.G.-R. has nothing to declare; E.B. has received honoraria for consultancy or lectures from Pharmanutra and Vifor Pharma; A.S. has received honoraria for consulting or lecturing from Masimo Corporation and Vifor Pharma; D.R.S. has received honoraria from Galenica, Pharmacosmos, Roche Diagnostics International Ltd, Roche Pharma, Sarstedt, and Vifor Pharma; M.M. has received honoraria for consultancy or lectures from Pharmacosmos, Pharmanutra, Vifor Pharma, Zambon, and Celgene.

\section{References}

1 WHO. Haemoglobin concentrations for the diagnosis of anaemia and assessment of severity. Vitamin and Mineral Nutrition Information System. Geneva: World Health Organization; 2011.

2 Kassebaum NJ, Jasrasaria R, Naghavi M, Wulf SK, Johns N, Lozano R, et al. A systematic analysis of global anemia burden from 1990 to 2010. Blood. 2014 Jan;123(5):615-24.

3 Vos T, Abajobir AA, Abate KH, Abbafati C, Abbas KM, Abd-Allah F, et al; GBD 2016 Disease and Injury Incidence and Prevalence Collaborators. Global, regional, and national incidence, prevalence, and years lived with disability for 328 diseases and injuries for 195 countries, 1990-2016: a systematic analysis for the Global Burden of Disease Study 2016 Lancet. 2017 Sep;390(10100):1211-59.

4 Muñoz M, Gómez-Ramírez S, Kozek-Langeneker S, Shander A, Richards T, Pavía J, et al. 'Fit to fly': overcoming barriers to preoperative haemoglobin optimization in surgical patients. Br J Anaesth. 2015 Jul;115(1):15-24.

5 Muñoz M, Acheson AG, Auerbach M, Besser $\mathrm{M}$, Habler $\mathrm{O}$, Kehlet $\mathrm{H}$, et al. International consensus statement on the peri-operative management of anaemia and iron deficiency. Anaesthesia. 2017 Feb;72(2):233-47.

6 Blaudszun G, Munting KE, Butchart A, Gerrard $\mathrm{C}$, Klein AA. The association between borderline pre-operative anaemia in women and outcomes after cardiac surgery: a cohort study. Anaesthesia. 2018 May;73(5):572-8.

7 Muñoz M, Laso-Morales MJ, Gómez-Ramírez S, Cadellas M, Núñez-Matas MJ, García-Erce JA. Pre-operative haemoglobin levels and iron status in a large multicentre cohort of patients undergoing major elective surgery. Anaesthesia. 2017 Jul;72(7):826-34.

8 Muñoz M, Gómez-Ramírez S, Cuenca J, García-Erce JA, Iglesias-Aparicio D, Haman-Alcober S, et al. Very-short-term perioperative intravenous iron administration and postoperative outcome in major orthopedic surgery: a pooled analysis of observational data from 2547 patients. Transfusion. 2014 Feb;54(2): 289-99.

9 Fowler AJ, Ahmad T, Phull MK, Allard S, Gillies MA, Pearse RM. Meta-analysis of the association between preoperative anaemia and mortality after surgery. Br J Surg. 2015 Oct; 102(11):1314-24.

10 Ranucci M, Di Dedda U, Castelvecchio S, Menicanti L, Frigiola A, Pelissero G; Surgical and
Clinical Outcome Research (SCORE) Group. Impact of preoperative anemia on outcome in adult cardiac surgery: a propensity-matched analysis. Ann Thorac Surg. 2012 Oct;94(4): 1134-41.

11 Piednoir P, Allou N, Driss F, Longrois D, Philip I, Beaumont C, et al. Preoperative iron deficiency increases transfusion requirements and fatigue in cardiac surgery patients: a prospective observational study. Eur J Anaesthesiol. 2011 Nov;28(11):796-801.

12 Miles LF, Kunz SA, Na LH, Braat S, Burbury K, Story DA. Postoperative outcomes following cardiac surgery in non-anaemic iron-replete and iron-deficient patients - an exploratory study. Anaesthesia. 2018 Apr;73(4): 450-8.

13 Shander A, Knight K, Thurer R, Adamson J, Spence R. Prevalence and outcomes of anemia in surgery: a systematic review of the literature. Am J Med. 2004 Apr;116(7 Suppl 7A): 58S-69S.

14 Muñoz M, Acheson AG, Bisbe E, Butcher A, Gómez-Ramírez S, Khalafallah AA, et al. An international consensus statement on the management of postoperative anaemia after major surgical procedures. Anaesthesia. 2018 Nov;73(11):1418-31.

15 Althoff FC, Neb H, Herrmann E, Trentino KM, Vernich L, Füllenbach C, et al. Multimodal Patient Blood Management Program Based on a Three-pillar Strategy: A Systematic Review and Meta-analysis. Ann Surg. 2018 Nov; DOI: 10.1097/SLA.0000000000003095.

16 Gómez Ramírez S, Remacha Sevilla ÁF, Muñoz Gómez M. Anaemia in the elderly. Med Clin (Barc). 2017 Dec 7;149(11):496-503.

17 Bisbe E, Basora M, Colomina MJ; Spanish Best Practice in Peri-operative Anaemia Optimisation Panel. Peri-Operative treatment of anaemia in major orthopaedic surgery: a practical approach from Spain. Blood Transfus. 2017 Jul;15(4):296-306.

18 NICE guideline [NG24]. Blood transfusion [Internet]. National Institute for Health and Care Excellence [cited 2017 Jun 27]. Available from: https://www.nice.org.uk/guidance/ng24/chapter/Recommendations\#alternatives-to-bloodtransfusion-for-patients-having-surgery-2 (accessed June 27/06/2017).

19 Muñoz M, Gómez-Ramírez S, Bhandari S. The safety of available treatment options for iron-deficiency anemia. Expert Opin Drug Saf. 2018 Feb;17(2):149-59.
20 Tolkien Z, Stecher L, Mander AP, Pereira DI, Powell JJ. Ferrous sulfate supplementation causes significant gastrointestinal side-effects in adults: a systematic review and meta-analysis. PLoS One. 2015 Feb; 10(2):e0117383.

21 Moretti D, Goede JS, Zeder C, Jiskra M, Chatzinakou V, Tjalsma H, et al. Oral iron supplements increase hepcidin and decrease iron absorption from daily or twice-daily doses in iron-depleted young women. Blood. 2015 Oct;126(17):1981-9.

22 Stoffel NU, Cercamondi CI, Brittenham G, Zeder C, Geurts-Moespot AJ, Swinkels DW, et al. Iron absorption from oral iron supplements given on consecutive versus alternate days and as single morning doses versus twice-daily split dosing in iron-depleted women: two open-label, randomised controlled trials. Lancet Haematol. 2017 Nov; 4(11):e524-33.

23 Rimon E, Kagansky N, Kagansky M, Mechnick L, Mashiah T, Namir M, et al. Are we giving too much iron? Low-dose iron therapy is effective in octogenarians. Am J Med. 2005 Oct;118(10):1142-7.

24 Scardino M, Di Matteo B, Martorelli F, Tanzi D, Kon E, D'Amato T. Improved patient blood management and cost saving in hip replacement surgery through the implementation of pre-operative Sucrosomial ${ }^{\circledR}$ iron supplementation: a quality improvement assessment study. Inter Orthop. 2019 Jan;43(1):39-46.

25 Kotzé A, Carter LA, Scally AJ. Effect of a patient blood management programme on preoperative anaemia, transfusion rate, and outcome after primary hip or knee arthroplasty: a quality improvement cycle. Br J Anaesth. 2012 Jun;108(6):943-52.

26 Pujol-Nicolas A, Morrison R, Casson C, Khan S, Marriott A, Tiplady C, et al. Preoperative screening and intervention for mild anemia with low iron stores in elective hip and knee arthroplasty. Transfusion. 2017 Dec;57(12): 3049-57.

27 Petis SM, Lanting BA, Vasarhelyi EM, Naudie DD, Ralley FE, Howard JL. Is there a role for preoperative iron supplementation in patients preparing for a total hip or total knee arthroplasty? J Arthroplasty. 2017 Nov;32(9): 2688-93

28 Muñoz M, Gómez-Ramírez S. Is there a role for iron supplementation in critically ill patients? Med Intensiva. 2018 Apr 12. pii: S02105691(18)30091-3 [Epub ahead of print]. 
29 Lewis GD, Malhotra R, Hernández AF, McNulty SE, Smith A, Felker GM, et al; NHLBI Heart Failure Clinical Research Network. Effect of oral iron repletion on exercise capacity in patients with heart failure with reduced ejection fraction and iron deficiency: the IRONOUT HF randomized clinical trial. JAMA. 2017 May;317(19):1958-66.

30 Bisbe E, Moltó L, Arroyo R, Muniesa JM, Tejero M. Randomized trial comparing ferric carboxymaltose vs oral ferrous glycine sulphate for postoperative anaemia after total knee arthroplasty. Br J Anaesth. 2014 Sep; 113(3):402-9.

31 Cladellas M, Farré N, Comín-Colet J, Gómez $\mathrm{M}$, Meroño O, Bosch MA, et al. Effects of preoperative intravenous erythropoietin plus iron on outcome in anemic patients after cardiac valve replacement. Am J Cardiol. 2012 Oct;110(7):1021-6.

32 Padmanabhan H, Siau K, Nevill AM, Morgan I, Cotton J, $\mathrm{Ng} \mathrm{A}$, et al. Intravenous iron does not effectively correct preoperative anaemia in cardiac surgery: a pilot randomized controlled trial. Interact Cardiovasc Thorac Surg. 2018 Aug; DOI: 10.1093/icvts/ivy226.

33 Goodnough LT, Maniatis A, Earnshaw P, Benoni G, Beris P, Bisbe E, et al. Detection, evaluation, and management of preoperative anaemia in the elective orthopaedic surgical patient: NATA guidelines. Br J Anaesth. 2011 Jan;106(1):13-22.

34 SABM. Anemia prevention and management program implementation guide, 2015 [cited 2018 Jul 11]. Available from: https://www. sabm.org/sites/default/files/anemia_prevention_management_program_implementation_guide.pdf.

35 Kotzé A, Harris A, Baker C, Iqbal T, Lavies N, Richards T, et al. British Committee for Standards in Haematology Guidelines on the Identification and Management of Pre-Operative Anaemia. Br J Haematol. 2015 Nov; 171(3):322-31.

36 Muñoz M, Gómez-Ramírez S, Besser M Pavía J, Gomollón F, Liumbruno GM, et al. Current misconceptions in diagnosis and management of iron deficiency. Blood Transfus. 2017 Sep;15(5):422-37.

37 Barton JC, Barton EH, Bertoli LF, Gothard $\mathrm{CH}$, Sherrer JS. Intravenous iron dextran therapy in patients with iron deficiency and normal renal function who failed to respond to or did not tolerate oral iron supplementation. Am J Med. 2000 Jul;109(1):27-32.

38 Gómez-Ramírez S, Shander A, Spahn DR, Auerbach M, Liumbruno GM, Vaglio S, et al. Prevention and management of acute reactions to intravenous iron in surgical patients. Blood Transfus. 2018 Oct;16:1-8.
39 European Medicines Agency. New Recommendations to Manage Risk of Allergic Reactions with Intravenous Iron Containing Medicines. EMA/579491/2013 [Internet]. London, European Medicines Agency [cited 2018 Jul 18]. Available from: http://www.ema. europa.eu/docs/en_GB/document_library/ Referrals_document/IV_iron_31/ WC500151308.pdf.

40 Macdougall IC, White C, Anker SD, Bhandari S, Farrington K, Kalra PA, et al; PIVOTAL Investigators and Committees. Intravenous iron in patients undergoing maintenance hemodialysis. N Engl J Med. 2019 Jan 31;380(5):447-58.

41 Zoller H, Schaefer B, Glodny B. Iron-induced hypophosphatemia: an emerging complication. Curr Opin Nephrol Hypertens. 2017 Jul; 26(4):266-75

42 Wolf M, Chertow GM, Macdougall IC, Kaper R, Krop J, Strauss W. Randomized trial of intravenous iron-induced hypophosphatemia. JCI Insight. 2018 Dec;3(23):124486.

43 Li Y, Yin P, Lv H, Meng Y, Zhang L, Tang P. A meta-analysis and systematic review evaluating the use of erythropoietin in total hip and knee arthroplasty. Ther Clin Risk Manag. 2018 Jul;14:1191-204.

44 Biboulet P, Bringuier S, Smilevitch P, Loupec T, Thuile C, Pencole M, et al. Preoperative epoetin- $\alpha$ with intravenous or oral iron for major orthopedic surgery: A randomized controlled trial. Anesthesiology. 2018 Oct; 129(4):710-20.

45 Theusinger OM, Kind SL, Seifert B, Borgeat L, Gerber C, Spahn DR. Patient blood management in orthopaedic surgery: a four-year follow-up from 2008 to 2011 at the Balgrist University Hospital in Zurich, Switzerland. Blood Transfus. 2014 Apr;12(2):195-203.

46 Yoo YC, Shim JK, Kim JC, Jo YY, Lee JH, Kwak YL. Effect of single recombinant human erythropoietin injection on transfusion requirements in preoperatively anemic patients undergoing valvular heart surgery. Anesthesiology. 2011 Nov;115(5):929-37.

47 Weltert L, Rondinelli B, Bello R, Falco M, Bellisario A, Maselli D, et al. A single dose of erythropoietin reduces perioperative transfusions in cardiac surgery: results of a prospective single-blind randomized controlled trial. Transfusion. 2015 Jul;55(7):1644-54.

48 Muñoz M, Gómez-Ramírez S, Martín-Montañez E, Auerbach M. Perioperative anemia management in colorectal cancer patients: a pragmatic approach. World J Gastroenterol. $2014 \mathrm{Feb} ; 20(8): 1972-85$.

49 Glaspy J, Crawford J, Vansteenkiste J, Henry D, Rao S, Bowers P, et al. Erythropoiesis-stimulating agents in oncology: a study-level meta-analysis of survival and other safety outcomes. Br J Cancer. 2010 Jan;102(2):301-15.

50 Moebus V, Jackisch C, Schneeweiss A, Huober J, Lueck HJ, du Bois A, et al; AGO Breast Study Group. Adding epoetin alfa to intense dose-dense adjuvant chemotherapy for breast cancer: randomized clinical trial. J Natl Cancer Inst. 2013 Jul;105(14):1018-26.
51 Aapro M, Beguin Y, Bokemeyer C, Dicato M, Gascón P, Glaspy J, et al; ESMO Guidelines Committee. Management of anaemia and iron deficiency in patients with cancer: ESMO Clinical Practice Guidelines. Ann Oncol. 2018 Oct:29 Suppl 4:iv96-110.

52 González-Pérez A, Al-Sibai JZ, ÁlvarezFernández P, et al. Liberal red blood cell transfusions impair quality of life after cardiac surgery. Med Intensiva. 2018 Mar 12. pii: S02105691(18)30041-X.

53 Acheson AG, Brookes MJ, Spahn DR. Effects of allogeneic red blood cell transfusions on clinical outcomes in patients undergoing colorectal cancer surgery: a systematic review and meta-analysis. Ann Surg. 2012 Aug; 256(2):235-44

54 Salpeter SR, Buckley JS, Chatterjee S. Impact of more restrictive blood transfusion strategies on clinical outcomes: a meta-analysis and systematic review. Am J Med. 2014 Feb; 127(2):124-131.e3.

55 Rohde JM, Dimcheff DE, Blumberg N, Saint S, Langa KM, Kuhn L, et al. Health care-associated infection after red blood cell transfusion: a systematic review and meta-analysis. JAMA. 2014 Apr;311(13):1317-26.

56 Goel R, Patel EU, Cushing MM, Frank SM, Ness PM, Takemoto CM, et al. Association of perioperative red blood cell transfusions with venous thromboembolism in a North American registry. JAMA Surg. 2018 Sep;153(9): $826-33$

57 Zhou X, Xu Z, Wang Y, Sun L, Zhou W, Liu $X$. Association between storage age of transfused red blood cells and clinical outcomes in critically ill adults: A meta-analysis of randomized controlled trials. Med Intensiva. 2018 Sep 18. pii: S0210-5691(18)30211-0.

58 Carson JL, Guyatt G, Heddle NM, Grossman BJ, Cohn CS, Fung MK, et al. Clinical Practice Guidelines from the AABB: Red Blood Cell Transfusion Thresholds and Storage. JAMA. 2016 Nov;316(19):2025-35.

59 Franchini M, Marano G, Mengoli C, Pupella S, Vaglio S, Muñoz M, et al. Red blood cell transfusion policy: a critical literature review. Blood Transfus. 2017 Jul;15(4):307-17.

60 Khalafallah AA, Yan C, Al-Badri R, Robinson E, Kirkby BE, Ingram E, et al. Intravenous ferric carboxymaltose versus standard care in the management of postoperative anaemia: a prospective, open-label, randomised controlled trial. Lancet Haematol. 2016 Sep;3(9):e41525.

61 Kim YW, Bae JM, Park YK, Yang HK, Yu W, Yook JH, et al; FAIRY Study Group. Effect of intravenous ferric carboxymaltose on hemoglobin response among patients with acute isovolemic anemia following gastrectomy: The FAIRY randomized clinical trial. JAMA. 2017;317:2097-104. 